\title{
Complications in TLIF spondylodesis-do they influence the outcome for patients? A prospective two-center study
}

\author{
Philipp Poppenborg $^{1}$ - Ulf Liljenqvist ${ }^{2}$. Georg Gosheger ${ }^{1}$. Albert Schulze Boevingloh ${ }^{1} \cdot$ Lukas Lampe $^{1}$. \\ Sebastian Schmeil ${ }^{2} \cdot$ Tobias L Schulte $^{3} \cdot$ Tobias Lange $^{3 \text { (D) }}$
}

Received: 28 March 2020 / Revised: 14 November 2020 / Accepted: 2 December 2020 / Published online: 22 December 2020

(c) The Author(s) 2020

\begin{abstract}
Purpose Transforaminal lumbar interbody fusion (TLIF) is a widely accepted surgical procedure for degenerative disk disease. While numerous studies have analyzed complication rates and risk factors this study investigates the extent to which complications after TLIF spondylodesis alter the clinical outcome regarding pain and physical function.

Methods A prospective clinical two-center study was conducted, including 157 patients undergoing TLIF spondylodesis with 12-month follow-up (FU). Our study classified complications into three subgroups: none (I), minor (IIa), and major complications (IIb). Complications were considered "major" if revision surgery was required or new permanent physical impairment ensued. Clinical outcome was assessed using visual analog scales for back (VAS-B) and leg pain (VAS-L), and Oswestry Disability Index (ODI).

Results Thirty-nine of 157 patients (24.8\%) had at least one complication during follow-up. At FU, significant improvement was seen for group I $(n=118)$ in VAS-B $(-50 \%)$, VAS-L $(-54 \%)$, and ODI $(-48 \%)$ and for group IIa $(n=27)$ in VAS-B $(-40 \%)$, VAS-L $(-64 \%)$, and ODI $(-47 \%)$. In group IIb $(n=12)$, VAS-B $(-22 \%, P=0.089)$ and ODI $(-33 \%, P=0.056)$ improved not significantly, while VAS-L dropped significantly less $(-32 \%, P=0.013)$ compared to both other groups.

Conclusion Our results suggest that major complications with need of revision surgery after TLIF spondylodesis lead to a significantly worse clinical outcome (VAS-B, VAS-L, and ODI) compared to no or minor complications. It is therefore vitally important to raise the surgeon's awareness of consequences of major complications, and the topic should be given high priority in clinical work.
\end{abstract}

Keywords TLIF $\cdot$ Spinal fusion $\cdot$ Complications $\cdot$ Clinical outcome $\cdot$ Pain

\section{Introduction}

Transforaminal lumbar interbody fusion (TLIF) in combination with spinal instrumented fusion using a pedicle screw rod system is a surgical technique that was first described in 1998 by Harms et al. [1]. It has been evolved from posterior interbody fusion (PLIF), which was first described by Briggs

Tobias Lange

tobias.lange-j3j@ruhr-uni-bochum.de

1 Department of Orthopaedics and Tumour Orthopaedics, Muenster University Hospital, Muenster, Germany

2 Department of Spine Surgery, St. Franziskus-Hospital, Muenster, Germany

3 Department of Orthopaedics and Trauma Surgery, St. Josef-Hospital, Ruhr-University Bochum, Bochum, Germany and was popularized by Cloward in the early 1950s [2]. Over the years, TLIF has become a widely used additional spinal fusion technique. It offers the potential advantages of anterior and posterior $360^{\circ}$ spinal column fusion, but with less morbidity due to the less invasive surgical approach [3]. Many authors consider that TLIF spondylodesis is the treatment of choice in surgical therapy for degenerative disk disease (DDD) [4-7]. The patient collective with DDD, involved in our study, were patients with discogenic low back pain, degenerative lumbar spondylolisthesis, or spinal stenosis in combination with disk degeneration.

Numerous studies have been published comparing the minimally invasive and classical open TLIF procedures [8-10]. Complication rates play a particularly important role in these studies and several other studies which further extensively concentrate on risk factors for complications and ways of preventing them [11-14]. Only a small number of 
studies have evaluated whether complications have a significant influence on the clinical outcome of back pain, leg pain, or physical function [4, 15-17]. This influence has been investigated by Glassman et al. but without focusing on any specific surgical technique [4]. Therefore, the present study focuses on the impact of complications on the clinical outcome after especially TLIF spondylodesis for DDD.

\section{Materials and methods}

\section{Patient group}

This prospective two-center study was conducted to test the hypothesis that complications after TLIF spondylodesis significantly influence the clinical outcome of pain and physical function. A total of 173 patients undergoing surgical treatment for DDD using the TLIF technique in single or multiple segments with the same type of pedicle screw rod system and TLIF cage in all cases were evaluated for study participation over a period of 16 months. Exclusion criteria were neurocognitive disorders making the patient unable to complete the study questionnaires correctly, prior operations in the relevant spine region, and planned surgical procedures with a technique other than TLIF. In total, 166 patients were enrolled. The first follow-up examination took place after 4 months and the second after 12 months [18-20]. Over the course of the study, patients who did not attend for the second follow-up appointment $(n=9)$ were excluded (lost to follow-up). Data for a total of 157 patients were therefore statistically analyzed in the study.

The enrolled patients were split into three study groups: those with no complications (group I), those with minor complications (group IIa), and those with major complications (group IIb).

The classification of complications was derived from Glassman et al. [4]. Major complications (IIb) comprised any surgical complication with a need for revision surgery; any new physical impairment; or the patient's death. All other complications with no need for further revision surgery, complications such as intraoperatively resolved accidental durotomy, conservative treatment of wound healing disorders, asymptomatic implant failure with solid bony fusion (checked by computed tomography), or general medical complications were considered as minor (IIa) $[4,21]$.

An a priori power analysis was performed based on comparable studies on clinical outcome after lumbar fusion surgery and showed a minimal clinically important difference (MCID) of two points on a 10-point scale on the visual analog scale (VAS), range: 0-10) [4, 15-17]. Using a power of $90 \%$ and an alpha level of 0.05 , it was determined that 134 patients were needed in order to detect a difference of 2 points on the average VAS between the different groups.

\section{Data}

The patients' data—gender, age, body mass index (BMI), and American Society of Anesthesiologists Physical Status Classification System (ASA status) — were collected preoperatively. The mean number of fused segments and operating time were documented postoperatively before discharge. Patient-reported outcome measures (PROMs) were used to assess pain intensity using visual analog scales for lumbar back pain (VAS-B) and radicular leg pain (VAS-L) [22]. The level of physical function was calculated on the basis of the Oswestry Disability Index (ODI) [15, 22]. Documentation of possible complications was carried out intraoperatively, postoperatively before discharge, and at both follow-up appointments (Table 1). The analysis of the clinical results is based on the 12-month follow-up findings, since individual revision operations had to be carried out 5-8 months after the initial TLIF procedure (Table 2).

\section{Statistics}

Descriptive values are given as mean $\pm S D$ for metric data. The alpha level was assigned as $P<0.05$. Parametric data were analyzed using paired $t$ tests, or with the Shapiro-Wilk test and Wilcoxon signed rank test if not normally distributed. Analysis of repeated measures with post hoc analysis according to Bonferroni was used for data comparison. Statistical analysis was performed using IBM SPSS Statistics, version 25.0 (IBM Corporation, Armonk, New York, USA).

\section{Results}

A total of 166 patients (113 women, 53 men) were enrolled in this prospective study. Nine patients were lost to followup, and therefore, data for 157 patients (105 women, 52 men) were statistically analyzed. The mean age of the patients analyzed was $62 \pm 15$ years.

No complications were observed in 118 of the 157 patients (75.2\%) (group I). Twenty-seven patients (17.2\%) suffered from minor complications (group IIa), and 12

Table 1 Questionnaires completed by the patients at different examination time points

\begin{tabular}{ll}
\hline Preoperative & ODI, VAS-B, VAS-L \\
\hline Postoperative (before discharge) & VAS-B, VAS-L \\
1st follow-up (4 months) & ODI, VAS-B, VAS-L \\
2nd follow-up (12 months) & ODI, VAS-B, VAS-L \\
\hline
\end{tabular}

$O D I$ Oswestry Disability Index; VAS-B visual analog scale for back pain; VAS- $L$ visual analog scale for leg pain 
Table 2 Frequency of minor complications (group IIa) and major complications (group IIb)

\begin{tabular}{|c|c|c|c|}
\hline Group & Complications & $\begin{array}{l}\text { Patients } \\
(n)\end{array}$ & $\begin{array}{l}\text { Time of revision } \\
\text { surgery after index } \\
\text { operation }\end{array}$ \\
\hline \multirow[t]{7}{*}{ IIa } & Minor & $27(17.2 \%)$ & \\
\hline & Superficial wound healing (conservative management) & 11 & - \\
\hline & Intraoperative solved accidentally durotomy with CSF leakage & 6 & - \\
\hline & Intraoperative pedicle fracture & 2 & - \\
\hline & Asymptomatic screw breakage with solid bony fusion at $12 \mathrm{~m} \mathrm{FU}$ & 1 & - \\
\hline & Transient dysesthesia (spontaneous recovery by the $4 \mathrm{~m} \mathrm{FU}$ at latest) & 3 & - \\
\hline & $\begin{array}{l}\text { General complications (cardiac arrhythmia; kidney failure; urogenital tract } \\
\text { infection, wound seroma) }\end{array}$ & 4 & - \\
\hline \multirow[t]{8}{*}{$\mathrm{IIb}$} & Major & $12(7.6 \%)$ & \\
\hline & Revision operations & $10(6.4 \%)$ & \\
\hline & Deep wound infection & 4 & $20-30$ days \\
\hline & Implant failure & 4 & $5-8$ months \\
\hline & Epidural hematoma & 1 & 4 days \\
\hline & New persistent neuropathic leg pain & 1 & 4 days \\
\hline & Persistent physical impairment (hemorrhagic cerebral insult) & 1 & \\
\hline & Death (septicemia with MODS due to wound infection) & 1 & \\
\hline
\end{tabular}

MODS multiple-organ dysfunction syndrome; $C S F$ cerebrospinal fluid

Kidney failure [40]: increase in serum creatinine ( $\mathrm{SCr}$ ) by $50 \%$ within 7 days or increase in $\mathrm{SCr}$ by $0,3 \mathrm{mg} / \mathrm{dl}$ within 2 days or oliguria

patients $(7.6 \%)$ had major complications (group IIb). The overall revision rate was $6.4 \%(n=10)$. One patient had persistent physical impairment due to a hemorrhagic cerebral insult, and another patient died due to multiple-organ dysfunction syndrome (MODS) resulting from septicemia due to a wound infection. Both of these cases were classified as major complications (Table 2) in addition to those who received a revision surgery which was median after 30 days after the initial operation.

Analysis of the patients' clinical and surgical parameters (age, BMI, ASA stage, number of fused segments, and operating time) showed that there were no significant differences between groups I, IIa, and IIb (Table 3).
The clinical outcome was assessed using the VAS-B, VAS-L, and ODI for each group at three different time points (Table 4).

\section{VAS-B}

In group I, the mean VAS-B score was $6.6 \pm 2.09$ preoperatively, improved significantly to $3.3 \pm 2.11$ postoperatively $(-50 \%, P<0.001)$ and remained constant at that level at the first $(-52 \%, P<0.001)$ and second $(-50 \%, P<0.001)$ followup examinations.

The mean VAS-B scores preoperatively were $6.7 \pm 2.55$ in group IIa and $8.2 \pm 1.47$ in group IIb. Both complication groups also showed an initial significant improvement in
Table 3 Relationship between clinical and surgical parameters and complications. Data are shown as mean $\pm S D$. ASA stage is shown as median

\begin{tabular}{|c|c|c|c|c|c|c|}
\hline & \multicolumn{3}{|l|}{ Group } & \multicolumn{3}{|l|}{$P$ values } \\
\hline & $\begin{array}{l}\mathrm{I} \\
(n=118)\end{array}$ & $\begin{array}{l}\text { IIa } \\
(n=27)\end{array}$ & $\begin{array}{l}\mathrm{IIb} \\
(n=12)\end{array}$ & I vs. IIa & I vs. IIb & IIa vs. IIb \\
\hline Sex (female:male) & $73: 45$ & $22: 5$ & $10: 2$ & 0.08 & 0.33 & 0.89 \\
\hline Age (y) & $62 \pm 15$ & $61 \pm 14$ & $65 \pm 16$ & 0.63 & 0.59 & 0.31 \\
\hline BMI $\left(\mathrm{kg} / \mathrm{m}^{2}\right)$ & $27.1 \pm 5.57$ & $27.3 \pm 4.74$ & $29.2 \pm 6.81$ & 0.99 & 0.33 & 0.74 \\
\hline ASA stage (median) & 2 & 2 & 2 & 0.08 & 0.91 & 0.43 \\
\hline 1st follow-up (months) & $4.0 \pm 0.89$ & $4.2 \pm 0.94$ & $5.0 \pm 1.31$ & & & \\
\hline 2nd follow-up (months) & $13.0 \pm 2.89$ & $15.5 \pm 6.21$ & $11.3 \pm 2.81$ & & & \\
\hline Fused segments $(n)$ & $1.5 \pm 0.72$ & $1.7 \pm 0.86$ & $2.0 \pm 1.04$ & 0.46 & 0.17 & 0.48 \\
\hline Operating time (min) & $170.3 \pm 59.72$ & $178 \pm 55.91$ & $222.6 \pm 83.14$ & 0.82 & 0.06 & 0.12 \\
\hline
\end{tabular}

ASA American Society of Anesthesiologists (classification); BMI body mass index 
Table 4 Clinical outcomes in groups I, IIa, and IIb at the three different time points (preoperative, postoperative, and 12-month follow-up). Data are shown as mean $\pm \mathrm{SD}$

\begin{tabular}{llll}
\hline Group & Preoperative & $\begin{array}{l}\text { Postoperative, } \\
\text { before discharge }\end{array}$ & 12-month \\
follow-up
\end{tabular}

$P$ values

Preoperative Preoperative Postoperative

vs. postoperative vs. 12 months vs. 12 months

\begin{tabular}{lcccccl}
\hline VAS- $B$ & & & & & \\
I & $6.6 \pm 2.09$ & $3.3 \pm 2.11$ & $3.3 \pm 2.58$ & $<0.001^{* *}$ & $<0.001^{* *}$ & 0.890 \\
IIa & $6.7 \pm 2.55$ & $3.2 \pm 1.97$ & $4.0 \pm 2.32$ & $<0.001^{* *}$ & $<0.001^{* *}$ & $0.034^{*}$ \\
IIb & $8.2 \pm 1.47$ & $3.1 \pm 1.58$ & $6.4 \pm 1.52$ & $<0.001^{* *}$ & 0.089 & $0.028^{*}$ \\
VAS-L & & & & & & \\
I & $6.6 \pm 2.62$ & $1.7 \pm 2.11$ & $2.9 \pm 2.80$ & $<0.001^{* *}$ & $<0.001^{* *}$ & $0.001^{* *}$ \\
IIa & $6.4 \pm 2.74$ & $2.3 \pm 2.67$ & $3.3 \pm 3.25$ & $<0.001^{* *}$ & $<0.001^{* *}$ & 0.131 \\
IIb & $7.6 \pm 2.02$ & $1.2 \pm 2.27$ & $5.2 \pm 1.92$ & $<0.001^{* *}$ & $0.013^{*}$ & 0.110 \\
ODI & & & & & & \\
I & $51.6 \pm 16.34$ & & $26.2 \pm 17.59$ & & $<0.001^{* *}$ & \\
IIa & $53.2 \pm 19.50$ & & $28.2 \pm 17.05$ & & $<0.001^{* *}$ & \\
IIb & $59.3 \pm 19.19$ & & $39.7 \pm 15.67$ & & 0.056 & \\
\hline
\end{tabular}

$O D I$ Oswestry Disability Index; VAS-B visual analog scale for back pain; $V A S-L$ visual analog scale for leg pain

$*$ A $P$ value of $<0.05$ was considered to indicate statistical significance

**A $P$ value of $<0.001$ was considered to indicate a high level of statistical significance the VAS-B with values of $3.2 \pm 1.97(-52 \% ; P<0.001)$ in group IIa and $3.1 \pm 1.58(-62 \%, P<0.001)$ in group IIb. But in contrast to group I the VAS-B score deteriorated again to $3.5 \pm 2.02(-48 \%, P<0.001)$ at the 4-month follow-up examination and to $4.0 \pm 2.32(-40 \%, P<0.001)$ at the 12-month follow-up appointment in group IIa. In group IIb, the VAS-B score worsened again to as much as $5.2 \pm 2.68$ $(-37 \%, P<0.001)$ at the first follow-up examination and to $6.4 \pm 1.52(-22 \%, P=0.089)$ at the second (Table 4, Fig. 1).

The improvement in the VAS-B score between the preoperative level and the 12-month follow-up was significantly lower $(P=0.039)$ in group IIb (major complications) in comparison with group I (no complications) (Table 5).

\section{VAS-L}

The mean preoperative VAS-L score in group I was $6.6 \pm 2.62$. The postoperative evaluation showed a significant reduction in the VAS-L score to $1.7 \pm 2.1(-74 \%$, $P<0.001)$. At the first $(2.5 \pm 2.7,-62 \%, P<0.001)$ and second $(2.9 \pm 2.8,-56 \%, P<0.001)$ follow-up appointments, a slight increase was observed in comparison with the
Fig. 1 Visual analog scale for back pain (VAS-B): preoperative, postoperative, 4-month and 12-month follow-up values in groups I, IIa, and IIb

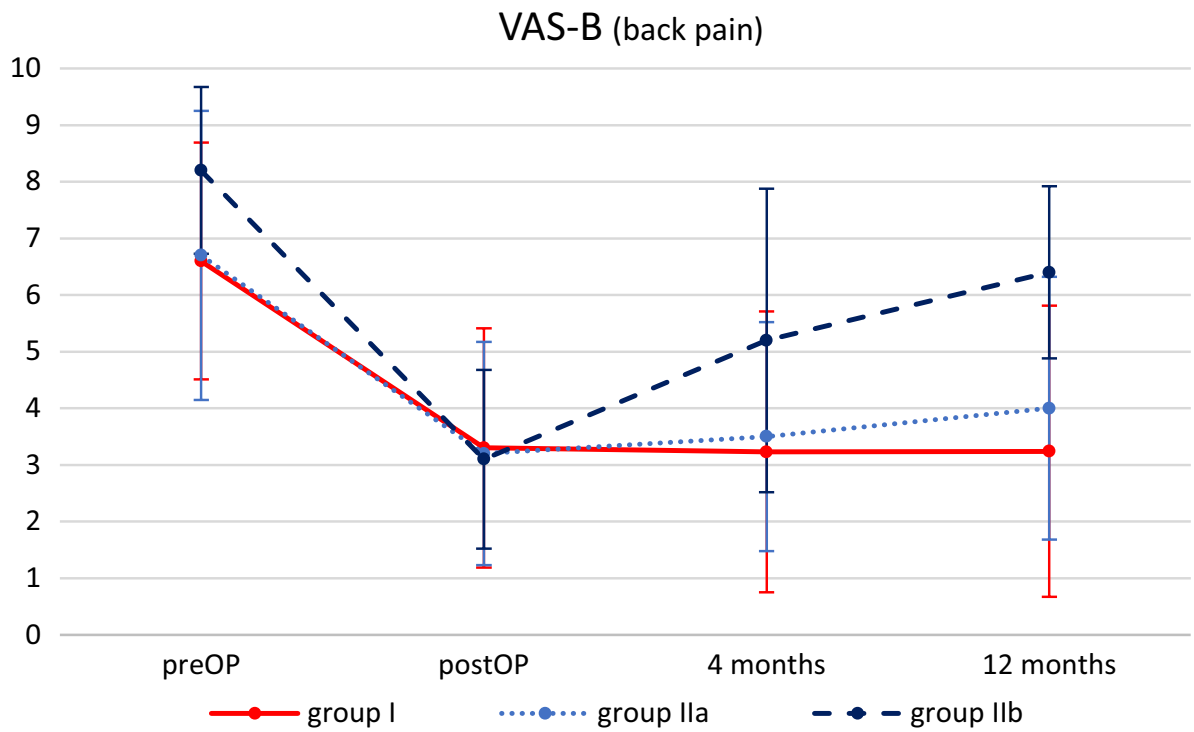


Table 5 Comparison of clinical outcome between groups I, IIa and IIb at the three different time points

\begin{tabular}{|c|c|c|c|c|c|c|}
\hline & \multicolumn{3}{|l|}{ Groups } & \multicolumn{3}{|l|}{$P$ values } \\
\hline & $\mathrm{I}(n=118)$ & IIa $(n=27)$ & $\operatorname{IIb}(n=12)$ & I vs. IIa & I vs. IIb & IIa vs. IIb \\
\hline \multicolumn{7}{|l|}{$V A S-B$} \\
\hline$\Delta$ (preoperative-postoperative) & 3.3 & 3.5 & 5.1 & 0.510 & 0.929 & 0.829 \\
\hline$\Delta$ (preoperative- -12 months) & 3.3 & 2.7 & 1.8 & 0.242 & $0.039 *$ & 0.973 \\
\hline \multicolumn{7}{|l|}{$V A S-L$} \\
\hline$\Delta$ (preoperative-postoperative) & 4.9 & 4.1 & 6.4 & 0.419 & 0.599 & 0.358 \\
\hline$\Delta$ (preoperative- -12 months) & 3.7 & 3.1 & 2.4 & 0.668 & 0.218 & 0.288 \\
\hline \multicolumn{7}{|l|}{$O D I$} \\
\hline$\Delta$ (preoperative- 12 months) & 25.4 & 25 & 19.6 & 0.454 & 0.585 & 0.347 \\
\hline
\end{tabular}

$\Delta$, difference in VAS-B, VAS-L, or ODI between two different time points; ODI Oswestry Disability Index; $V A S-B$ visual analog scale for back pain; $V A S-L$ visual analog scale for leg pain

*A $P$ value of $<0.05$ was considered to indicate statistical significance immediate postoperative value, but a significant decrease in comparison with the preoperative level was still present.

The VAS-L values in groups IIa and IIb showed the same trend already observed in group I. Postoperative VAS-L values improved significantly to $2.3 \pm 2.67(-64 \%, P<0.001)$ in group IIa and to $1.2 \pm 2.27(-84 \%, P<0.001)$ in group IIb. The VAS-L in both complication groups deteriorated gradually to $3.3 \pm 3.25(-48 \%, P<0.001)$ in group IIa and to $5.2 \pm 1.92(-32 \%, P<0.05)$ in group IIb at the 12 -month follow-up examination (Table 4, Fig. 2). Intergroup comparison with the extent of VAS-L improvement between the preoperative and 12-month values did not show any significant differences (Table 5).

\section{ODI}

In group I, the ODI averaged $51.6 \pm 16.34$ preoperatively and improved significantly to $29.6 \pm 17.93(-43 \%$,
$P<0.001)$ at the 4-month follow-up examination and to $26.2 \pm 17.59(-49 \%, P<0.001)$ at the 12 -month appointment.

A similar improvement in ODI was seen in group IIa, with a significant decrease from $53.2 \pm 19.50$ preoperatively to $35.3 \pm 16.32$ at the first follow-up examination $(-34 \%, P<0.001)$ and to $28.2 \pm 17.05$ at the second $(-47 \%$, $P<0.001$ ) (Table 4, Fig. 3).

In contrast, ODI showed only a slight and nonsignificant improvement in group IIb $(-33 \%, P=0.056$ at the 12-month follow-up examination) (Table 4, Fig. 3). Intergroup analysis of the improvement in the ODI between the preoperative and 12-month examinations showed no significant differences, but there was a considerable trend toward poorer physical function in group IIb after 12 months (Table 5, Fig. 3).
Fig. 2 Visual analog scale for leg pain (VAS-L): preoperative, postoperative, 4-month and 12-month follow-up values in groups I, IIa, and IIb

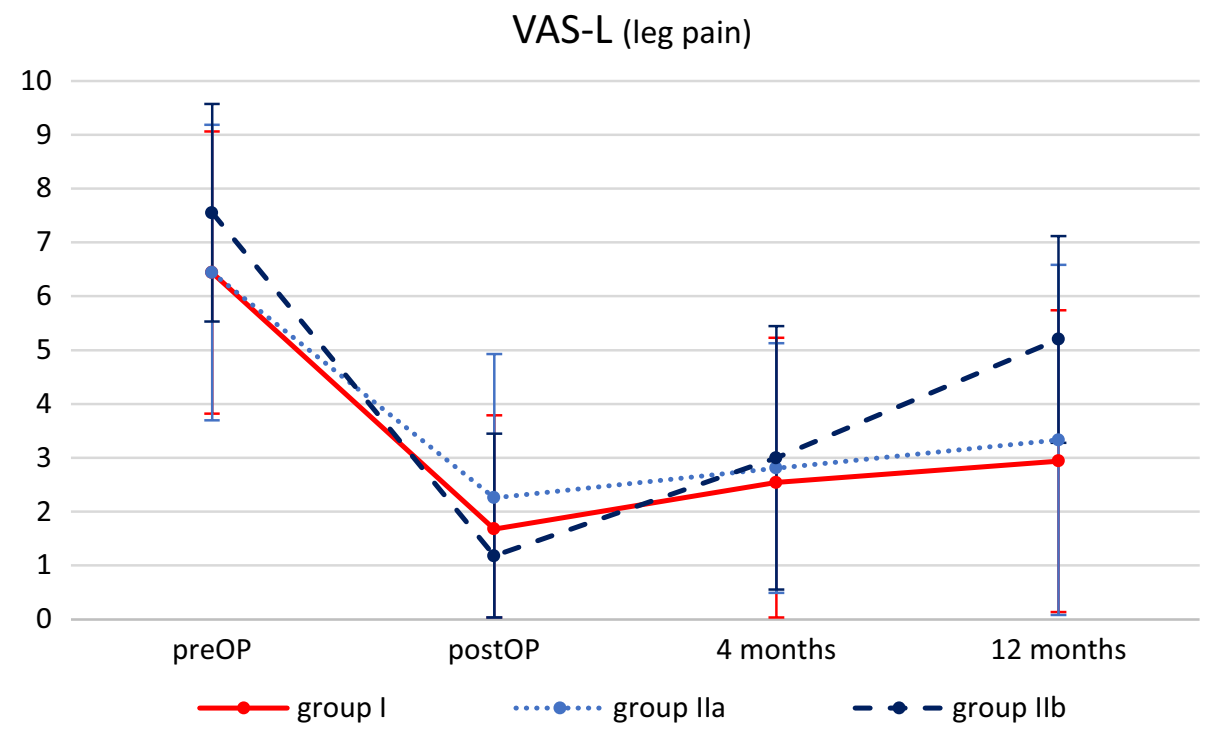


Fig. 3 Oswestry Disability Index (ODI) scores: preoperative, postoperative, 4-month and 12-month follow-up values in groups I, IIa, and IIb

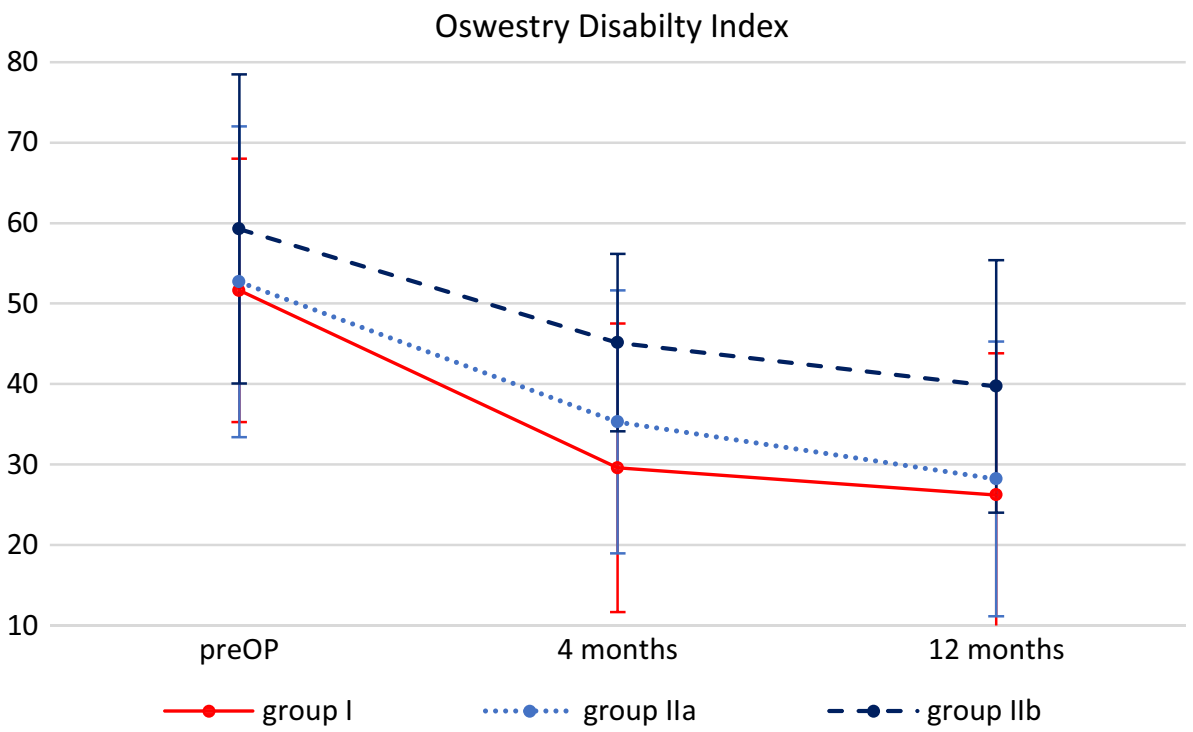

\section{Discussion}

TLIF spondylodesis is widely used in lumbar spine fusion, particularly in patients with DDD or in corrective surgery in those with adult spinal deformity. Earlier studies have identified risk factors for the occurrence of complications, such as age, comorbidities, operating time, and low bone mineral density, for example [23-26]. The number and type of complications are criteria commonly used to evaluate the success of spinal surgical procedures [27, 28]. There is a consensus that spinal surgery may be considered safe and reliable if the complication rate for the procedure is as low as possible. Only a few studies have investigated the impact of complications that occur on the clinical outcome in general, and none has so far focused on TLIF spondylodesis [4, $21,29]$.

Reports in the current literature show that complication rates associated with lumbar fusion operations vary considerably between 8.8 and $50 \%$, also leading to a wide range of revision surgery rates of between 1.9 and $27 \%$ [28, 30-32]. The present prospective study indicated a similar overall complication rate of $24.8 \%$ and a revision surgery rate of $6.4 \%$. Many documentations use the Clavien-Dindo classification to report surgery-related morbidity and mortality. This classification is specialized in reporting postoperative complications especially in general surgery. Although other specializations apart from general surgery have modified and adopted this classification to their needs, we decided to use the Glassman classification [4]. Glassman et al. have developed this classification system especially for adult spinal deformity surgery focusing on whether perioperative complications alter the subsequent clinical outcome, the same question we investigated in our study concerning TLIF surgery. Different to the Clavien-Dindo classification
Glassman et al. distinguish between intra-, postoperative, and complications noted at follow-up, which is necessary for investigating the influence of complications related to TLIF spondylodesis on the "long term" clinical outcome.

The wide range of complications and rates of revision surgery can generally be explained by the varying definitions used and different systems for classifying complications, as well as nonhomogeneous study populations and different surgical techniques-e.g., minimally invasive vs. classical open techniques [30, 31, 33].

The present study was clearly not designed to identify physical and mental risk factors for complications. Instead, it investigated whether minor and major complications alter the clinical outcome compared to patients without any complications. Although the study design did not allow randomization of the patients, there were no relevant differences between the three study groups in relation to clinical parameters such as age, BMI, and ASA stage, or surgical parameters such as the number of fused segments and operating time.

The results of this study indicate that minor complications with no need for revision surgery have a limited impact on the clinical outcome after 12 months of follow-up. There were no significant differences in relation to improvement in lumbar back pain, radicular leg pain, or physical function between the group with no complications and the group with minor complications. This finding is consistent with the report by Glassman et al. [4], who also found no significant differences in pain or physical function between patients without and with minor complications after spinal surgeryalthough the authors did not focus on a specific surgical technique such as classical open TLIF spondylodesis, as in the present study [4]. It can be assumed that minor complications do have a short-term effect and do not totally alter 
the healing process, and therefore do not have a significant impact on the longer-term course.

In contrast, patients with major complications had an initial postoperative improvement in lumbar back pain and radicular leg pain, but there was a significant deterioration in both parameters at the 12-month follow-up examination in comparison with patients who had minor intraoperative or postoperative complications, or no complications at all. Physical function, measured using the ODI, improved significantly between the preoperative examination and the 12-month follow-up in the two groups with no complications or minor complications. In the patient group suffering from major complications, no significant improvement in ODI was observed in this study - a finding that is consistent with the further deterioration of VAS-B and VAS-L scores after 12 months of follow-up in this group. We are aware that especially in this group the mental constitution might be an influencing factor and limitation of this study which we explicitly have not tested for.

Postoperatively, the promising reduction in back and radicular leg pain is likely to be influenced by effective postoperative pain management. Particularly for postoperative values, therefore, the absence of data concerning analgesic treatment is an important limiting factor in this study. However, it can be assumed that all of the patients received the same pain medication regime.

From the surgical point of view, on the one hand, clinical parameters such as the VAS-B, VAS-L, and ODI scores are the most interesting parameters for both the patient and surgeon for assessing the success of a surgical intervention. On the other hand, there may be complications that do not directly affect these clinical parameters, while others dramatically alter the patient's long-term medical status, and these are therefore inadequately reflected using PROMs alone. As PROMs are affected by patients' perception of disease and are influenced by the patients' points of view, feelings, and attitudes, the concept of a minimal clinically important difference (MCID) is needed in order to interpret improvement or deterioration in PROMs [34]. The MCID describes a benchmark for clinically meaningful improvement for a PROM with patient benefit [34]. Several studies have used visual analog scales for pain scores, with different results for minimal clinically important differences in the pain outcome [35-38]. According to Lord et al., a difference in a VAS pain score of two points on a 10-point scale can be regarded as indicating a significant clinical difference [38]. In the present study, only group IIb did not show any significant and clinically meaningful improvement in the intensity of back pain measured with VAS-B at the 12-month follow-up examination. In the other groups with no complications or minor complications, the improvements in the intensity of back and leg pain measured with VAS-B and VAS-L were significantly to the patients' benefit clinically. In the study by Ostelo et al., the MCID for the ODI was set to 10 points, or a $30 \%$ improvement in comparison with the baseline [39]. In the present study, the ODI improved by 19.6-25.4 points, or $33-49 \%$, between the preoperative and 12-month followup examinations in all three groups. The ODI thus showed a significant clinical difference in all groups. However, it needs to be borne in mind that the ODI improvement in group IIb, at $33 \%$, was only just above the presented cutoff value of $30 \%$ [39].

The results of the present study suggest that minor complications have no substantial effects on the primary clinical outcome in TLIF spondylodesis in comparison with major complications. A clinically important difference could not be detected. It is therefore reasonable to inform surgical patients about possible complications and their frequency, but also to point out that the impact of minor complications appears to be limited.

In contrast, major complications continue to be a genuine problem in relation to the clinical outcome. These occurred in approximately $8 \%$ of cases in this study and clearly affected the outcome. A recurrent deterioration in the VAS-B and VAS-L scores 1 year after surgery, following initial postoperative clinical improvement, and a markedly lower improvement in the ODI were observed in patients with major complications in comparison with patients who had no complications or only minor ones.

There were only 12 patients in group IIb with a risk of type 1 error and follow-up was 12 months. We are aware, that the small number of cases limits the power of evidence in this complication group. In particular, in this group the preoperative constitution might influence the severity of complications and the postoperative course, and finally, we are not able to stratify for potential baseline risk factors. Therefore, future studies with bigger sample size and greater numbers of revisions in a prospective setting are needed to assure our results that major complications besides other preoperative risk factors are relevant in terms of clinical outcome after TLIF spondylodesis. While risk factors for complications have been already investigated in a sufficient quantity, in further studies it would be interesting to see which risk factors are significantly related to major complications. Notwithstanding these important limitations, our data are collected prospectively which increase the level of evidence and clinical relevance compared to large multicenter retrospective registry studies. Furthermore, all data were collected in two centers in a standardized way. Nevertheless, larger future studies in a prospective setting may elucidate more detailed information why patients with major complications after TLIF surgery may benefit less from surgery. 


\section{Conclusions}

Minor complications do not have any minimal clinically important difference and therefore no relevant influence on the clinical outcome after a follow-up period of 12 months, in contrast to major complications. Patients with major complications have limited benefit from TLIF spondylodesis in relation to lumbar back pain and physical function. These findings are important for the process of shared decision-making during the patients' preparation for the surgical intervention. It is therefore vitally important to raise the surgeon's awareness of consequences of major complications and the topic should be given high priority in clinical work.

Author contributions Poppenborg, Liljenqvist, and Schulte contributed to conceptualization and methodology. Poppenborg, Lange, and Schmeil were involved in formal analysis and investigation. Poppenborg, Lange contributed to writing-original draft preparation. Poppenborg, Lampe, and Lange were involved in writing-review and editing. Gosheger, Schulze Boevingloh, and Liljenqvist contributed to resources. Lange was involved in supervision.

Funding Open Access funding enabled and organized by Projekt DEAL

Data availability All data generated or analyzed during this study are included in this article.

\section{Compliance with ethical standards}

Conflicts of interest The author(s) declare that they have no competing interests.

Ethics approval The study protocol was approved by the regional ethics committee (AZ: 2011-632-f-S).

Open Access This article is licensed under a Creative Commons Attribution 4.0 International License, which permits use, sharing, adaptation, distribution and reproduction in any medium or format, as long as you give appropriate credit to the original author(s) and the source, provide a link to the Creative Commons licence, and indicate if changes were made. The images or other third party material in this article are included in the article's Creative Commons licence, unless indicated otherwise in a credit line to the material. If material is not included in the article's Creative Commons licence and your intended use is not permitted by statutory regulation or exceeds the permitted use, you will need to obtain permission directly from the copyright holder. To view a copy of this licence, visit http://creativecommons.org/licenses/by/4.0/.

\section{References}

1. Harms JG, Jeszenszky D (1998) Die posteriore, lumbale, interkorporelle Fusion in unilateraler transforaminaler Technik (Not Available). Operative Orthopadie und Traumatologie 10(2):90102. https://doi.org/10.1007/s00064-006-0112-7
2. Lewandrowski KU (2003) Abvances in spinal fusion: Molecular Science, BiocMechanics, and Clinical Management. CRC Press, IBAN

3. Saville PA, Anari JB, Smith HE, Arlet V (2016) Vertebral body fracture after TLIF: a new complication. Eur Spine J 25(Suppl 1):230-238. https://doi.org/10.1007/s00586-016-4517-1

4. Glassman SD, Hamill CL, Bridwell KH, Schwab FJ, Dimar JR, Lowe TG (2007) The impact of perioperative complications on clinical outcome in adult deformity surgery. Spine 32(24):27642770. https://doi.org/10.1097/BRS.0b013e31815a7644

5. McAfee PC, DeVine JG, Chaput CD, Prybis BG, Fedder IL, Cunningham BW, Farrell DJ, Hess SJ, Vigna FE (2005) The indications for interbody fusion cages in the treatment of spondylolisthesis: analysis of 120 cases. Spine 30(6 Suppl):S60 S65. https://doi.org/10.1097/01.brs.0000155578.62680.dd

6. Giorgi H, Prébet R, Delhaye M, Aurouer N, Mangione P, Blondel B, Tropiano P, Fuentes S, Parent H-F (2015) Minimally invasive posterior transforaminal lumbar interbody fusion: One-year postoperative morbidity, clinical and radiological results of a prospective multicenter study of 182 cases. OTSR 101(6 Suppl):S241S245. https://doi.org/10.1016/j.otsr.2015.07.001

7. Brantigan JW, Neidre A, Toohey JS (2004) The Lumbar I/F Cage for posterior lumbar interbody fusion with the variable screw placement system: 10-year results of a Food and Drug Administration clinical trial. Spine Journal 4(6):681-688. https://doi. org/10.1016/j.spinee.2004.05.253

8. Makanji H, Schoenfeld AJ, Bhalla A, Bono CM (2018) Critical analysis of trends in lumbar fusion for degenerative disorders revisited: influence of technique on fusion rate and clinical outcomes. Eur Spine J 27(8):1868-1876. https://doi.org/10.1007/ s00586-018-5544-x

9. Saetia K, Phankhongsab A, Kuansongtham V, Paiboonsirijit S (2013) Comparison between minimally invasive and open transforaminal lumbar interbody fusion. J Med Assoc Thailand $=$ Chotmaihet thangphaet 96(1):41-46

10. Wang J, Zhou Y, Zhang ZF, Li CQ, Zheng WJ, Liu J (2011) Minimally invasive or open transforaminal lumbar interbody fusion as revision surgery for patients previously treated by open discectomy and decompression of the lumbar spine. Eur spine $\mathrm{J}$ 20(4):623-628. https://doi.org/10.1007/s00586-010-1578-4

11. Faciszewski T, Winter RB, Lonstein JE, Denis F, Johnson L (1995) The surgical and medical perioperative complications of anterior spinal fusion surgery in the thoracic and lumbar Spine in adults. Spine 20(14):1592-1599. https://doi.org/10.1097/00007 632-199507150-00007

12. Baron EM, Albert TJ (2006) Medical complications of surgical treatment of adult spinal deformity and how to avoid them. Spine 31(19 Suppl):S106-S118. https://doi.org/10.1097/01.brs.00002 32713.69342.df

13. Urban MK, Jules-Elysee KM, Beckman JB, Sivjee K, King T, Kelsey W, Boachie-Adjei O (2005) Pulmonary injury in patients undergoing complex spine surgery. spine J 5(3):269-276. https:// doi.org/10.1016/j.spinee.2004.10.049

14. McDonnell MF, Glassman SD, Dimar JR, Puno RM, Johnson JR (1996) Perioperative complications of anterior procedures on the spine. J bone joint surg Am 78(6):839-847. https://doi. org/10.2106/00004623-199606000-00006

15. Hägg O, Fritzell P, Nordwall A (2003) The clinical importance of changes in outcome scores after treatment for chronic low back pain. Eur spine J 12(1):12-20. https://doi.org/10.1007/s0058 6-002-0464-0

16. Crandall DG, Revella J (2009) Transforaminal lumbar interbody fusion versus anterior lumbar interbody fusion as an adjunct to posterior instrumented correction of degenerative lumbar scoliosis: three year clinical and radiographic outcomes. Spine 
34(20):2126-2133. https://doi.org/10.1097/BRS.0b013e3181 b612db

17. Rodríguez-Vela J, Lobo-Escolar A, Joven E, Muñoz-Marín J, Herrera A, Velilla J (2013) Clinical outcomes of minimally invasive versus open approach for one-level transforaminal lumbar interbody fusion at the 3- to 4-year follow-up. Eur spine $\mathbf{J}$ 22(12):2857-2863. https://doi.org/10.1007/s00586-013-2853-y

18. Adogwa O, Elsamadicy AA, Han JL, Cheng J, Karikari I, Bagley CA (2016) Do measures of surgical effectiveness at 1 year after lumbar spine surgery accurately predict 2-year outcomes?, J Neurosurg: Spine SPI, 25(6), 689-696. Retrieved Jul 19, 2020, from https://thejns.org/spine/view/journals/j-neurosurg-spine/25/6/artic le-p689.xml

19. Kubota G, Kamoda H, Orita S, Inage K, Ito M, Yamashita M, Furuya T, Akazawa T, Shiga Y, Ohtori S (2018) Efficacy of Platelet-Rich Plasma for Bone Fusion in Transforaminal Lumbar Interbody Fusion. Asian spine J 12(1):112-118. https://doi. org/10.4184/asj.2018.12.1.112

20. Høy K, Truong K, Andersen T, Bünger C (2017) Addition of TLIF does not improve outcome over standard posterior instrumented fusion. 5-10 years long-term Follow-up: results from a RCT. Eur spine J 26(3):658-665. https://doi.org/10.1007/s0058 6-016-4592-3

21. Emami A, Deviren V, Berven S, Smith JA, Hu SS, Bradford DS (2002) Outcome and complications of long fusions to the sacrum in adult spine deformity: luque-galveston, combined iliac and sacral screws, and sacral fixation. Spine 27(7):776-786. https:// doi.org/10.1097/00007632-200204010-00017

22. Haefeli M, Elfering A (2006) Pain assessment. Eur spine J 15(Suppl 1):S17-24. https://doi.org/10.1007/s00586-005-1044-X

23. Anand N, Rosemann R, Khalsa B, Baron EM (2010) Mid-term to long-term clinical and functional outcomes of minimally invasive correction and fusion for adults with scoliosis. Neurosurg Focus 28(3):E6. https://doi.org/10.3171/2010.1.FOCUS09272

24. Zanirato A, Damilano M, Formica M, Piazzolla A, Lovi A, Villafañe JH, Berjano P (2018) Complications in adult spine deformity surgery: a systematic review of the recent literature with reporting of aggregated incidences. Eur spine J 27(9):2272-2284. https:// doi.org/10.1007/s00586-018-5535-y

25. Steiger F, Becker H-J, Standaert CJ, Balague F, Vader J-P, Porchet F, Mannion AF (2014) Surgery in lumbar degenerative spondylolisthesis: indications, outcomes and complications A systematic review. Eur spine J 23(5):945-973. https://doi.org/10.1007/ s00586-013-3144-3

26. Yan D-L, Li J, Gao L-B, Soo CL (2008) Comparative study on two different methods of lumbar interbody fusion with pedicle screw fixation for the treatment of spondylolisthesis. Zhonghua wai ke za zhi [Chinese journal of surgery] 46(7):497-500

27. Fritzell P, Hägg O, Nordwall A (2003) Complications in lumbar fusion surgery for chronic low back pain: comparison of three surgical techniques used in a prospective randomized study A report from the Swedish Lumbar Spine Study Group. Eur spine J 12(2):178-189. https://doi.org/10.1007/s00586-002-0493-8

28. Carreon LY, Puno RM, Dimar JR, Glassman SD, Johnson JR (2003) Perioperative complications of posterior lumbar decompression and arthrodesis in older adults. J bone joint surg Am 85(11):2089-2092
29. Albert TJ, Purtill J, Mesa J, McIntosh T, Balderston RA (1995) Health outcome assessment before and after adult deformity surgery A prospective study. Spine 20(18):2002-4. https://doi. org/10.1097/00007632-199509150-00009

30. Deyo RA, Martin BI, Kreuter W, Jarvik JG, Angier H, Mirza SK (2011) Revision surgery following operations for lumbar stenosis. J bone joint surg Am 93(21):1979-1986. https://doi.org/10.2106/ JBJS.J.01292

31. Kobayashi K, Ando K, Kato F, Kanemura T, Sato K, Hachiya Y, Matsubara Y, Kamiya M, Sakai Y, Yagi H, Shinjo R, Nishida Y, Ishiguro N, Imagama S (2018) Reoperation within 2 years after lumbar interbody fusion: a multicenter study. Eur spine J 27(8):1972-1980. https://doi.org/10.1007/s00586-018-5508-1

32. Nguyen TH, Randolph DC, Talmage J, Succop P, Travis R (2011) Long-term outcomes of lumbar fusion among workers' compensation subjects: a historical cohort study. Spine 36(4):320-331. https ://doi.org/10.1097/BRS.0b013e3181ccc220

33. Jin-Tao Q, Yu T, Mei W, Xu-Dong T, Tian-Jian Z, Guo-Hua S, Lei C, Yue H, Zi-Tian W, Yue Z (2015) Comparison of MIS vs open PLIF/TLIF with regard to clinical improvement, fusion rate, and incidence of major complication a meta-analysis. Eur spine $\mathbf{J}$ 24(5):1058-1065. https://doi.org/10.1007/s00586-015-3890-5

34. Sedaghat AR (2019) Understanding the Minimal Clinically Important Difference (MCID) of Patient-Reported Outcome Measures. Otolaryngol-head neck surg 161(4):551-560. https:// doi.org/10.1177/0194599819852604

35. Lee JS (2003) Clinically Important Change in the Visual Analog Scale after Adequate Pain Control. Acad Emerg Med 10(10):1128-1130. https://doi.org/10.1197/S1069-6563(03)00372 $-5$

36. Todd KH, Funk JP (1996) The minimum clinically important difference in physician-assigned visual analog pain scores. Acad Emerg Med 3(2):142-146. https://doi. org/10.1111/j.1553-2712.1996.tb03402.x

37. Kelly AM (2001) Setting the benchmark for research in the management of acute pain in emergency departments. Emerg med (fremantle, W.A.) 13(1):57-60. https://doi.org/10.104 6/j.1442-2026.2001.00179.x

38. Lord BA, Parsell B (2003) Measurement of pain in the prehospital setting using a visual analogue scale. Prehosp disaster med 18(4):353-358. https://doi.org/10.1017/s1049023x0000131x

39. Ostelo RWJG, Deyo RA, Stratford P, Waddell G, Croft P, von Korff M, Bouter LM, de Vet HC (2008) Interpreting change scores for pain and functional status in low back pain: towards international consensus regarding minimal important change. Spine 33(1):90-94. https://doi.org/10.1097/BRS.0b013e31815e3a10

40. Kidney Disease: Improving Global Outcomes (KDIGO) CKD Work Group 2012 KDIGO 2012 clinical practice guideline for the evaluation and management of chronic kidney disease Kidney International Supplements $211 \mathrm{https} / / /$ doi.org/10.1038/kisup .2012 .1

Publisher's Note Springer Nature remains neutral with regard to jurisdictional claims in published maps and institutional affiliations. 